\title{
Dynamic soil-structure interaction effects on 3D integral railway bridge under high-speed moving loads
}

\author{
Anand M. Gharad* and Ranjan S. Sonparote \\ Department of Applied Mechanics, Visvesvaraya National Institute of Technology, Nagpur 440 010, India
}

Here, we have studied a ballastless double-track fivespan integral bridge subjected to China Railway High-speed train loading. Soil-structure interaction (SSI) is considered to assess the resonant response of each span of this bridge. Finite element method is used to analyse the 3D bridge model. Four soil conditions, viz. fixed base, hard soil, medium soil and soft soil are considered to examine the dynamic response of the bridge. For each soil condition and for all the spans, it is observed that the resonant speeds correspond to higher modal frequencies. This study reveals the occurrence of resonance phenomenon for all the spans of an integral bridge, suggesting the importance of moving load analysis. Finally, the vertical resonant responses of the central span of an integral bridge and a continuous bridge are compared.

Keywords: Finite element analysis, integral railway bridge, moving loads, soil-structure interaction.

IN the last few years, study on different aspects of integral railway bridges has gained the attention of several researchers. An integral bridge is a monolithic bridge construction. The advantages of such a construction are that it is ductile, durable, requires less maintenance cost, has no movement of joints in the deck slab and transmits horizontal loads to the ground move effectively compared to conventional bridges ${ }^{1}$. The disadvantage of such a construction includes irregular displacements due to thermal expansion and contraction of the deck slab at abutments and piers ${ }^{2,3}$. The study of dynamic response of integral bridges subjected to seismic excitations is a significant research area $^{4,5}$.

The effects of speed-induced vibrations on different types of railway bridges have been studied by numerous researchers in the past ${ }^{6-9}$. Three-dimensional bridge models with various boundary/soil conditions have also been studied $^{10,11}$. The aforementioned bridges are either simply supported and/or continuous. The dynamic response of such bridges emphasized the importance of resonance excitation obtained under various train speeds.

\footnotetext{
*For correspondence. (e-mail: anandgharad@gmail.com)
}

For the integral bridges present worldwide, research mainly focuses on two aspects, viz. cyclic variation due to temperature effects, and braking and seismic forces. Ülker-Kaustell et al. ${ }^{12}$ have performed the dynamic soilstructure interaction (SSI) analysis of a 2D portal frame subjected to various train loads. However, no substantial work related to the identification of resonance phenomenon of 3D multi-span integral bridge under the moving loads is available in the literature. Thus, in the present study moving load analysis (MLA) is performed to determine the dynamic response of the aforementioned full-scale integral bridge. Ballastless double-track is assumed to be a part of this bridge. A simple approach of MLA is adopted. Since only the bridge-deck response in vertical and lateral directions is evaluated, the track irregularities need not be considered, and hence are neglected $^{13}$. China Railway High-speed (CRH3) train loading is considered to be passing over a single track of the fivespan integral bridge. Four different soils below the foundations, viz. fixed base, hard soil, medium soil and soft soil are considered, and the dynamic analysis for each soil type is carried out and compared. Finally, for medium soil condition, the resonance responses of integral and continuous bridge are compared.

The main purpose of this study is to provide design engineers a simplified approach to assess the dynamic response of an integral bridge subjected to high-speed moving loads. A commercial software package SAP2000 (ref. 14) was used to conduct the dynamic SSI analysis.

\section{Integral bridge model}

An integral bridge model shown in Figure 1 is considered for the present study. The bridge consists of rails, ballastless tracks (two numbers), bridge-deck slab, integral abutments and piers. Table 1 provides details of various components of the integral bridge. Figure 2 shows the finite element model used to represent the bridge. The rails and piers are modelled as frame elements, bridge deck and abutments as shell elements, and the soil is represented by springs and dampers (dashpots). The dynamic interaction between railway tracks and bridge deck is simulated using spring-damper (link) elements. 
Figure 3 shows the connectivity details of a combined ballastless track element comprising rails, rail pads, cement asphalt mortar (CAM) layer and deck slab.

\section{Moving load and soil model}

CRH3 high-speed train of total length $200 \mathrm{~m}$ is assumed to be moving on one of the tracks. The axle loads for motor cars (two numbers) and passenger cars (six numbers) are taken as 160 and $146 \mathrm{kN}$ respectively. The characteristic distance $d$ is considered as $25 \mathrm{~m}$. A simple moving load model is adopted to study the soil-bridge interaction, which excludes the inertia effect of the vehicle.

Table 1. Parameters considered for the integral bridge structure

\begin{tabular}{|c|c|c|c|}
\hline Description & Value & Unit & Ref. \\
\hline \multicolumn{4}{|l|}{ Rails } \\
\hline Young's modulus & $2.1 \times 10^{8}$ & $\mathrm{kN} / \mathrm{m}^{2}$ & 20 \\
\hline $\begin{array}{l}\text { Flexural moment of inertia about } \\
\text { minor axis of cross-section }\end{array}$ & $3.2 \times 10^{-5}$ & $\mathrm{~m}^{4}$ & \\
\hline $\begin{array}{l}\text { Flexural moment of inertia about } \\
\text { major axis of cross-section }\end{array}$ & $5.24 \times 10^{-6}$ & $\mathrm{~m}^{4}$ & \\
\hline Mass per unit length & 60.64 & $\mathrm{~kg} / \mathrm{m}$ & \\
\hline \multicolumn{4}{|l|}{ Rail pads } \\
\hline Horizontal stiffness & $50 \times 10^{3}$ & $\mathrm{kN} / \mathrm{m}$ & 21 \\
\hline Horizontal damping & 60 & $\mathrm{kN}-\mathrm{s} / \mathrm{m}$ & \\
\hline Vertical stiffness & $30 \times 10^{3}$ & $\mathrm{kN} / \mathrm{m}$ & \\
\hline Vertical damping & 50 & $\mathrm{kN}-\mathrm{s} / \mathrm{m}$ & \\
\hline Interval/spacing & 0.60 & $\mathrm{~m}$ & \\
\hline \multicolumn{4}{|c|}{ Cement Asphalt Mortar (CAM) layer } \\
\hline Stiffness & $0.9 \times 10^{3}$ & $\mathrm{MN} / \mathrm{m}$ & 22 \\
\hline Damping & 80 & $\mathrm{kN}-\mathrm{s} / \mathrm{m}$ & \\
\hline \multicolumn{4}{|c|}{ Girder, Abutments, Piers and Pier Foundations } \\
\hline Young's modulus & $2.9 \times 10^{7}$ & $\mathrm{kN} / \mathrm{m}^{2}$ & 2 \\
\hline Height of piers & 12 & $\mathrm{~m}$ & \\
\hline Diameter of piers & 1.0 & $\mathrm{~m}$ & \\
\hline Abutment width & 14.4 & $\mathrm{~m}$ & \\
\hline Abutment height & 3.3 & $\mathrm{~m}$ & \\
\hline Foundation $(L \times B \times H)$ & $7 \times 5 \times 1.5$ & $\mathrm{~m}$ & \\
\hline
\end{tabular}
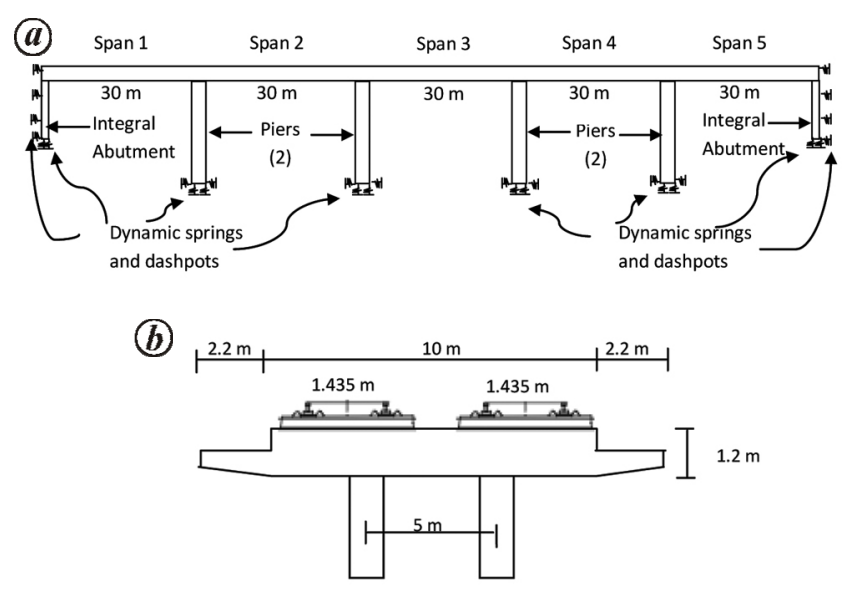

Figure 1. (a) Elevation and (b) cross-sectional details of the integral bridge.
The soil stratum below the foundations of structures considerably affects the dynamic response of the structures. In this study, the dynamic soil spring constants in all the six directions were evaluated using the well-established formulations presented by Gazetas ${ }^{15}$ (Table 2). Four soil conditions, namely fixed base, hard soil, medium soil and soft soil (depending on the shear wave velocities) were used. Table 3 gives different shear wave velocity values according to soil classification given in the Uniform Building Code (UBC, 1997). The soil density value of $18 \mathrm{kN} / \mathrm{m}^{3}$ was chosen and soil adjoining the abutments was considered as medium soil throughout the study. Table 4 provides evaluated values for the vertical, horizontal, lateral, rocking (about the horizontal and lateral) and torsion components of dynamic stiffness and damping for the hard, medium and soft soils.

In Table 2, $\chi=A_{\mathrm{b}} / 4 L^{2} A_{\mathrm{b}}$ is the area of the foundation considered; $I_{\mathrm{bx}}, I_{\mathrm{by}}$ and $I_{\mathrm{bz}}$ are the moments of inertia about the $x, y$ and $z$ axes respectively, of the actual soilfoundation contact surface; $B$ and $L$ are half width and half length of a rectangular foundation respectively; $G$ is the shear modulus and $v$ is the Poisson's ratio of the soil (considered as 0.35 ), and $V_{\mathrm{s}}$ and $V_{\mathrm{La}}$ are the shear-wave velocity and Lysmer's analog wave velocity respectively. The values of the dynamic stiffness coefficients $\tilde{k}_{x}, \tilde{k}_{y}, \tilde{k}_{z}, \tilde{k}_{r x}, \tilde{k}_{r y}$ and $\tilde{k}_{t}$ and the dynamic damping coefficients $\tilde{c}_{x}, \tilde{c}_{y}, \tilde{c}_{z}, \tilde{c}_{r x}, \tilde{c}_{r y}$ and $\tilde{c}_{t}$ can be obtained from the relevant charts proposed by Gazetas ${ }^{15}$.

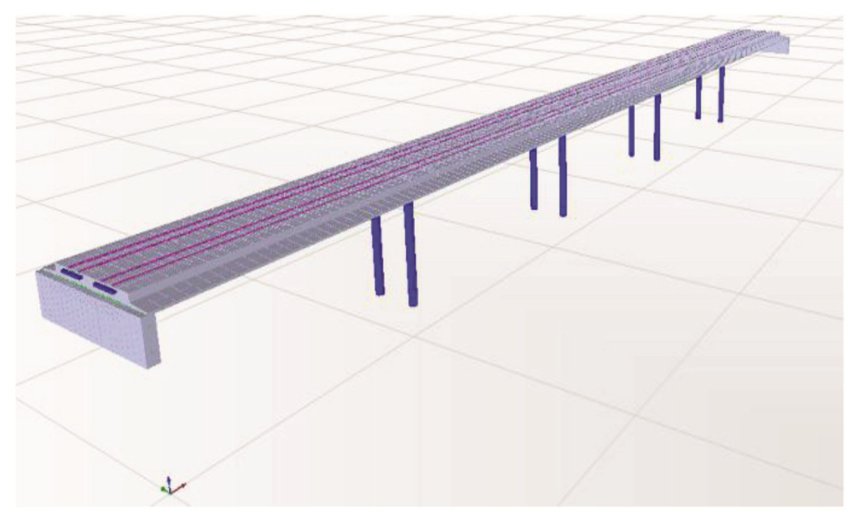

Figure 2. Full-scale 3D finite element model of the integral bridge.

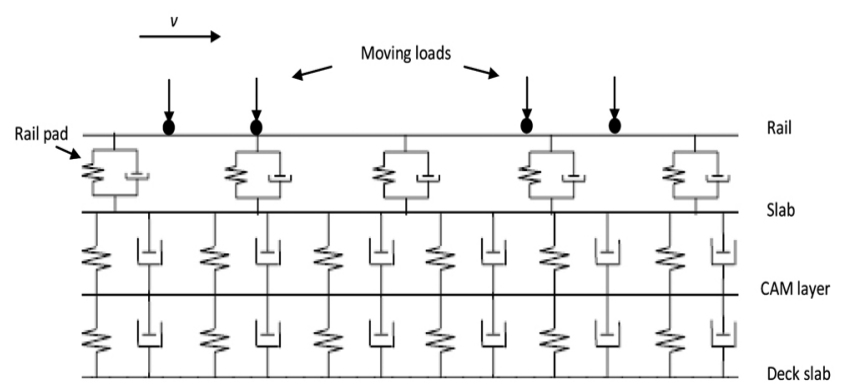

Figure 3. Ballastless bridge deck slab model (longitudinal section). 


\section{RESEARCH ARTICLES}

Table 2. Equivalent dynamic spring stiffness and dashpot values along various degrees of freedom ${ }^{15}$

\begin{tabular}{lll}
\hline Degrees of freedom & Stiffness of equivalent soil spring & Radiation dashpot coefficient \\
\hline Vertical & $\tilde{K}_{z}=(2 G L /(1-v))\left(0.73+1.54 \chi^{0.75}\right) \cdot\left(\tilde{k}_{z}\right)$ & $C_{z}=\left(\rho V_{\mathrm{La}} A_{b}\right) \cdot \bar{c}_{z}$ \\
Horizontal (lateral direction) & $\tilde{K}_{y}=(2 G L /(2-v))\left(2+2.50 \chi^{0.85}\right) \cdot\left(\tilde{k}_{y}\right)$ & $C_{y}=\left(\rho V_{s} A_{b}\right) \cdot \bar{c}_{y}$ \\
Horizontal (longitudinal direction) & $\tilde{K}_{x}=\left(\tilde{K}_{y}-(0.2 /(0.75-v)) G L(1-(B / L))\right) \cdot\left(\tilde{k}_{x}\right)$ & $C_{x}=\left(\rho V_{s} A_{b}\right)$ \\
Rocking (about the longitudinal, $x$-axis) & $\tilde{K}_{r x}=(G /(1-v)) I_{b x}^{0.75}(L / B)^{0.25}(2.4+0.5(B / L)) \cdot\left(\tilde{k}_{r x}\right)$ & $C_{r x}=\left(\rho V_{\mathrm{La}} I_{b x}\right) \cdot \bar{c}_{r x}$ \\
Rocking (about the lateral, $y$-axis) & $\tilde{K}_{r y}=(3 G /(1-v)) I_{b y}^{0.75}(L / B)^{0.15} \cdot\left(\tilde{k}_{r y}\right)$ & $C_{r y}=\left(\rho V_{\mathrm{La}} I_{b y}\right) \cdot \bar{c}_{r y}$ \\
Torsion & $\tilde{K}_{t}=3.5 G I_{b z}^{0.75}(B / L)^{0.4}\left(I_{b z} / B^{4}\right)^{0.2} \cdot\left(\tilde{k}_{t}\right)$ & $C_{t}=\left(\rho V_{s} I_{b z}\right) \cdot \bar{c}_{t}$ \\
\hline
\end{tabular}

Table 3. Modal information of the integral bridge for different soil conditions

\begin{tabular}{|c|c|c|c|c|}
\hline \multirow{2}{*}{$\begin{array}{l}\text { Mode } \\
\text { number }\end{array}$} & \multicolumn{4}{|c|}{ Modal frequencies $(\mathrm{Hz})$ for various soil types (shear wave velocity $v_{\mathrm{s}}$ ) and nature of each mode } \\
\hline & Fixed base $(-)$ & Hard $(400 \mathrm{~m} / \mathrm{s})$ & Medium $(250 \mathrm{~m} / \mathrm{s})$ & Soft $(150 \mathrm{~m} / \mathrm{s})$ \\
\hline 1 & 1.626 (lateral floating) & 1.616 (lateral floating) & 1.607 (lateral floating) & 1.581 (lateral floating) \\
\hline 2 & $\begin{array}{l}2.300 \text { (first vertical } \\
\text { symmetrical bending) }\end{array}$ & $\begin{array}{l}2.297 \text { (first vertical } \\
\text { symmetrical bending) }\end{array}$ & $\begin{array}{l}2.285 \text { (first vertical } \\
\text { symmetrical bending) }\end{array}$ & $\begin{array}{l}2.270 \text { (first vertical } \\
\text { symmetrical bending) }\end{array}$ \\
\hline 3 & $\begin{array}{l}2.780 \text { (second vertical } \\
\text { symmetrical bending) }\end{array}$ & $\begin{array}{l}2.769 \text { (first vertical } \\
\text { anti-symmetrical bending) }\end{array}$ & $\begin{array}{l}2.747 \text { (first vertical } \\
\text { symmetrical bending) }\end{array}$ & $\begin{array}{l}2.696 \text { (vertical } \\
\text { anti-symmetrical bending) }\end{array}$ \\
\hline 4 & $\begin{array}{l}3.390 \text { (vertical } \\
\text { anti-symmetrical bending) }\end{array}$ & $\begin{array}{l}3.364 \text { (second vertical } \\
\text { symmetrical bending) }\end{array}$ & $\begin{array}{l}3.321 \text { (second vertical } \\
\text { symmetrical bending) }\end{array}$ & $\begin{array}{l}3.200 \text { (second vertical } \\
\text { symmetrical bending) }\end{array}$ \\
\hline 5 & 3.944 (twisting) & $\begin{array}{l}3.900 \text { (second vertical } \\
\text { anti-symmetrical bending) }\end{array}$ & $\begin{array}{l}3.832 \text { (second vertical } \\
\text { anti-symmetrical bending) }\end{array}$ & 3.653 (lateral bending) \\
\hline
\end{tabular}

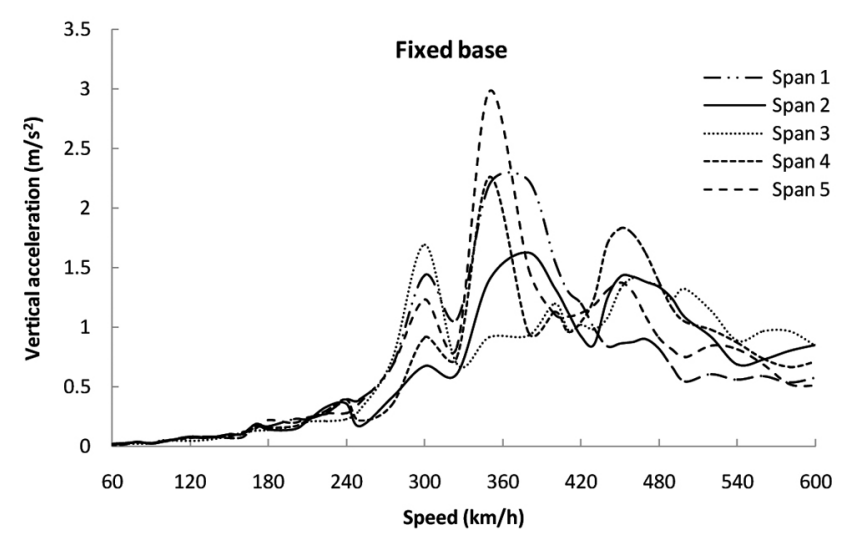

Figure 4. Maximum mid-span bridge deck vertical acceleration response with varying train speeds.

\section{Moving load analysis using finite element method}

The dynamic equations of the bridge system subjected to moving forces is represented as

$$
[M]\left\{\ddot{U}_{\mathrm{b}}\right\}+[C]\left\{\dot{U}_{\mathrm{b}}\right\}+[K]\left\{U_{\mathrm{b}}\right\}=\left\{F_{\mathrm{b}}\right\}
$$

where $[M],[C],[K]$ respectively, represent the mass, damping and stiffness of the entire bridge system, $\left\{U_{\mathrm{b}}\right\}$ the bridge displacement, $\left\{\dot{U}_{\mathrm{b}}\right\}$ the velocity, $\left\{\ddot{U}_{\mathrm{b}}\right\}$ the acceleration and $\left\{F_{b}\right\}$ the external moving loads acting on the bridge. Equation (1) is a typical second-order differential equation, which can be solved by number of timemarching schemes. Newmark- $\beta$ method with Newmark's parameters $\beta=1 / 4$ and $\gamma=1 / 2$, have been used in this study to determine the dynamic response of the bridge ${ }^{16}$. Rayleigh damping coefficients, evaluated using the modal damping ratio, have been adopted. The first five natural frequencies were used in the present study ${ }^{17}$. Table 3 provides modal analysis information of the integral bridge for all the considered soil types.

\section{Analysis of integral bridge}

The modal analysis was carried out to identify the resonance response of this bridge subjected to moving loads. The first five mode shapes and modal frequencies were noted. Table 3 summarizes the modal information of different soil types along with their shear wave velocities below the pier foundations. The backfill soil behind the abutments are considered to be medium soil with shear wave velocity as $v_{\mathrm{s}}=250 \mathrm{~m} / \mathrm{s}$.

The modal damping ratio is required for dynamic soilbridge interaction analysis under moving loads. Table 5 shows the structural modal damping (\%) values for different soil types obtained by free vibration analysis considering $1 \%$ modal damping for the fixed base 
RESEARCH ARTICLES

Table 4. Dynamic stiffness and dashpot values for different soil conditions

\begin{tabular}{lcccc}
\hline Description & Degree of freedom & Hard soil & Medium soil & Soft soil \\
\hline Dynamic stiffness (kN/m) & $\tilde{K}_{x}$ & $4.59 \times 10^{6}$ & $1.79 \times 10^{6}$ & $6.46 \times 10^{5}$ \\
& $\tilde{K}_{y}$ & $4.74 \times 10^{6}$ & $1.85 \times 10^{6}$ & $6.66 \times 10^{5}$ \\
& $\tilde{K}_{z}$ & $5.98 \times 10^{6}$ & $2.33 \times 10^{6}$ & $8.40 \times 10^{5}$ \\
& $\tilde{K}_{r x}$ & $3.32 \times 10^{7}$ & $1.30 \times 10^{7}$ & $4.66 \times 10^{6}$ \\
& $\tilde{K}_{r y}$ & $5.78 \times 10^{7}$ & $2.26 \times 10^{7}$ & $8.13 \times 10^{6}$ \\
Dynamic damping (kN-s/m) & $\tilde{K}_{t}$ & $1.50 \times 10^{7}$ & $5.88 \times 10^{6}$ & $2.12 \times 10^{6}$ \\
& $C_{x}$ & $3.73 \times 10^{4}$ & $2.38 \times 10^{4}$ & $1.48 \times 10^{4}$ \\
& $C_{y}$ & $3.73 \times 10^{4}$ & $2.38 \times 10^{4}$ & $1.48 \times 10^{4}$ \\
& $C_{z}$ & $7.79 \times 10^{4}$ & $4.87 \times 10^{4}$ & $2.92 \times 10^{4}$ \\
& $C_{r x}$ & $5.35 \times 10^{4}$ & $3.34 \times 10^{4}$ & $2.01 \times 10^{4}$ \\
& $C_{r y}$ & $1.22 \times 10^{5}$ & $7.62 \times 10^{4}$ & $4.57 \times 10^{4}$ \\
\hline
\end{tabular}

Table 5. Modal damping ratios for various soil types

\begin{tabular}{lc}
\hline Soil type & Modal damping (\%) \\
\hline Fixed base & 1.0 \\
Hard & 1.4 \\
Medium & 1.7 \\
Soft & 2.3 \\
\hline
\end{tabular}

condition $^{18}$. A hypothetical case for the fixed base condition was studied to observe the mid-deck maximum acceleration response of the integral bridge. Single-track loading was considered for the study. Figure 4 shows the variation of maximum mid-deck vertical acceleration for all the five spans of the bridge with train speeds, varying from 60 to $600 \mathrm{~km} / \mathrm{h}$, with an increment of $10 \mathrm{~km} / \mathrm{h}$.

\section{Integral bridge response}

From Figure 4 it can be observed that the maximum dynamic response is below $380 \mathrm{~km} / \mathrm{h}$. Most of the highspeed trains run at an operating speed ranging between 200 and $250 \mathrm{~km} / \mathrm{h}$. Thus, for further dynamic analysis, train speeds were varied from 60 to $380 \mathrm{~km} / \mathrm{h}$. The midspan dynamic response of the bridge deck in both vertical and lateral directions was studied. The maximum displacement and acceleration values of the mid-span with respect to varying train speeds on a single track for all the spans of the integral bridge in these two directions were evaluated (Figures 5-9).

Figure $5 a$ represents mid-span vertical displacement of span 1 for various soil conditions. The train load enters span 1 and departs from span 5. For a bridge subjected to moving loads, the resonant speed can be evaluated using eq. (2) below ${ }^{21}$

$$
v_{\mathrm{brn}}=\frac{3.6 \cdot f_{\mathrm{bn}} d}{i}(n=1,2,3 \ldots ; i=1,2,3 \ldots),
$$

where $v_{\text {brn }}$ is the resonant moving train velocity $(\mathrm{km} / \mathrm{h})$; $f_{\text {bn }}$ the $n$th natural frequency of the beam $(\mathrm{Hz}) ; d$ the cha- racteristic distance of the moving high speed trains (m; considered as $25 \mathrm{~m}$ in the present study) and $i$ represents the number of complete oscillation cycles for the $n$th mode of the bridge to vibrate during the passage of two adjacent loads.

Two resonance peaks of span 1 corresponding to mode numbers 4 and 5 were observed for fixed base, hard and medium soils. It was observed that with increase in the speed, there was an increase in displacement and acceleration. At resonance, the peak values differed; this was due to the fact that the amplitude of resonance reduced with higher damping ratio. For soft soil, single resonance peak was observed corresponding to mode number 5 . In Figure $5 b$, a similar response for the mid-span vertical acceleration of span 1 can be observed. Figure $5 c$ and $d$ shows the mid-span lateral displacement and acceleration values of span 1 for various soil conditions.

Figure $6 a$ and $b$ shows the mid-span vertical displacement and acceleration plot of span 2 with increasing train speed. These responses increased with speed for the considered soil types. From the vertical acceleration response, the resonant speed was adjacent to mode number 5. Figure $6 c$ and $d$ represents the mid-span lateral displacement and acceleration values of span 2 for different soil conditions.

Figure $7 a$ and $b$ shows the mid-span dynamic response of span 3 (centre span). This span represents a single resonant peak for all soil types. It can be noted that the peaks obtained for fixed base, hard and medium soils are mostly at similar resonant speeds. From Table 3 it is evident that natural frequencies for mode number 4 (for fixed base, hard and medium soils) are comparable. Figure $7 c$ and $d$ represents the mid-span lateral displacement and acceleration values of span 3 for different soil conditions.

Figure $8 a$ and $b$ shows the dynamic response of span 4 for various soil conditions with increasing train speed. Resonant velocity was obtained at mode number 5. Figure $8 c$ and $d$ represents the mid-span lateral displacement and acceleration values of span 4 for different soil conditions. 

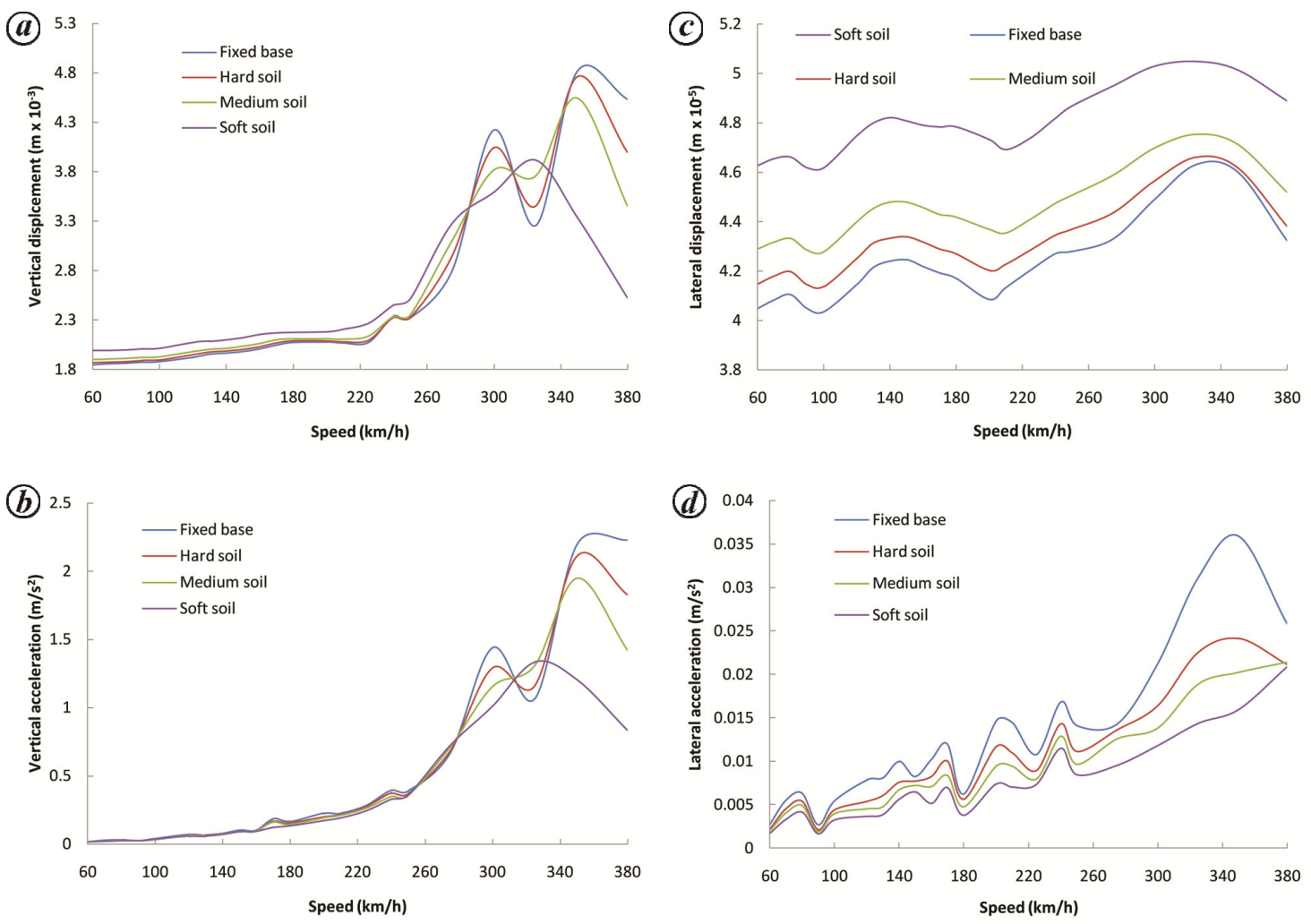

Figure 5. Mid-span maximum vertical and lateral displacement $(\boldsymbol{a}, \boldsymbol{c})$ and acceleration $(\boldsymbol{b}, \boldsymbol{d})$ response with varying train speeds of span 1 of the integral bridge.
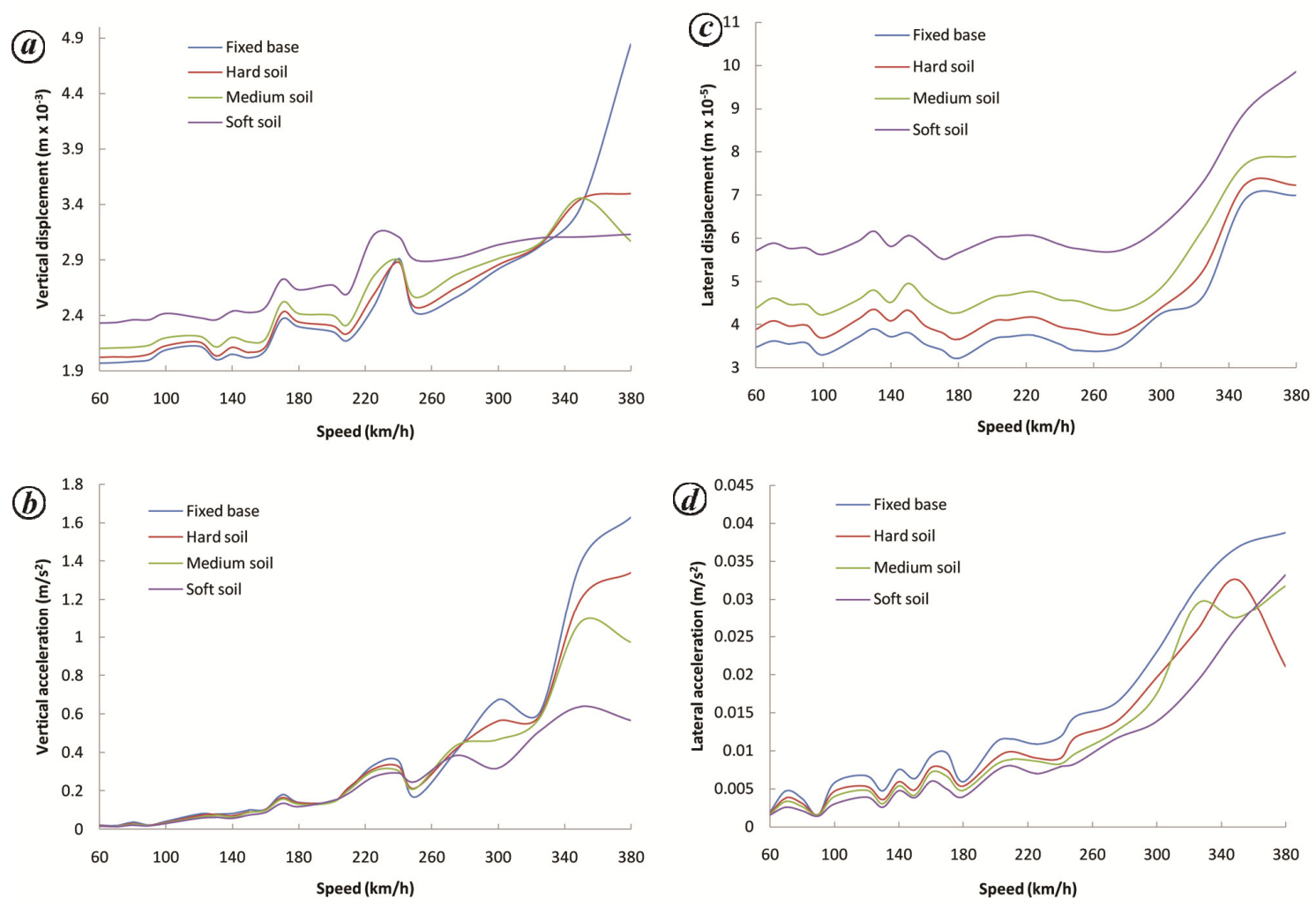

Figure 6. Mid-span maximum vertical and lateral displacement $(\boldsymbol{a}, \boldsymbol{c})$ and acceleration $(\boldsymbol{b}, \boldsymbol{d})$ response with varying train speeds of span 2 of the integral bridge. 

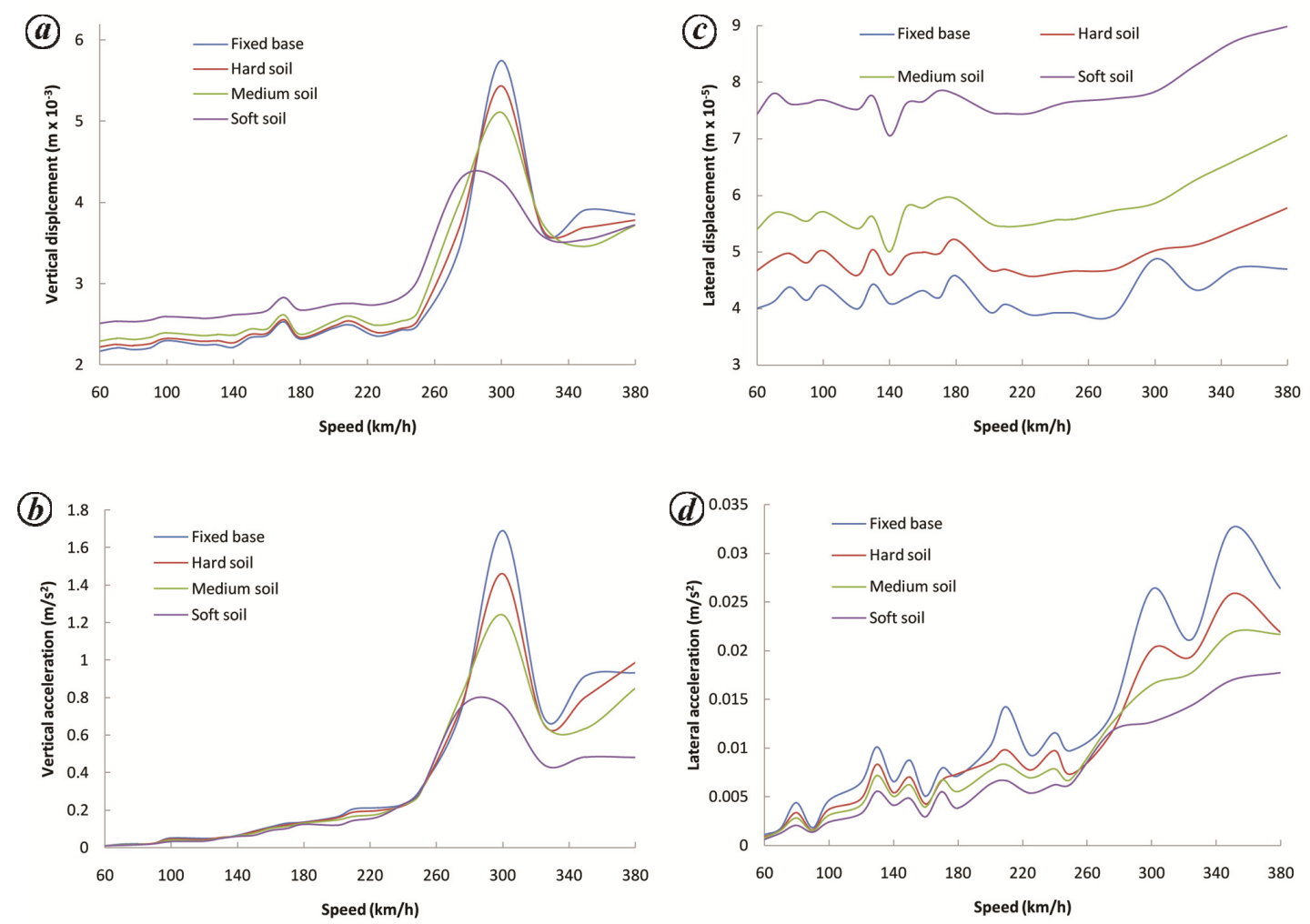

Figure 7. Mid-span maximum vertical and lateral displacement $(\boldsymbol{a}, \boldsymbol{c})$ and acceleration $(\boldsymbol{b}, \boldsymbol{d})$ response with varying train speeds of span 3 of the integral bridge.
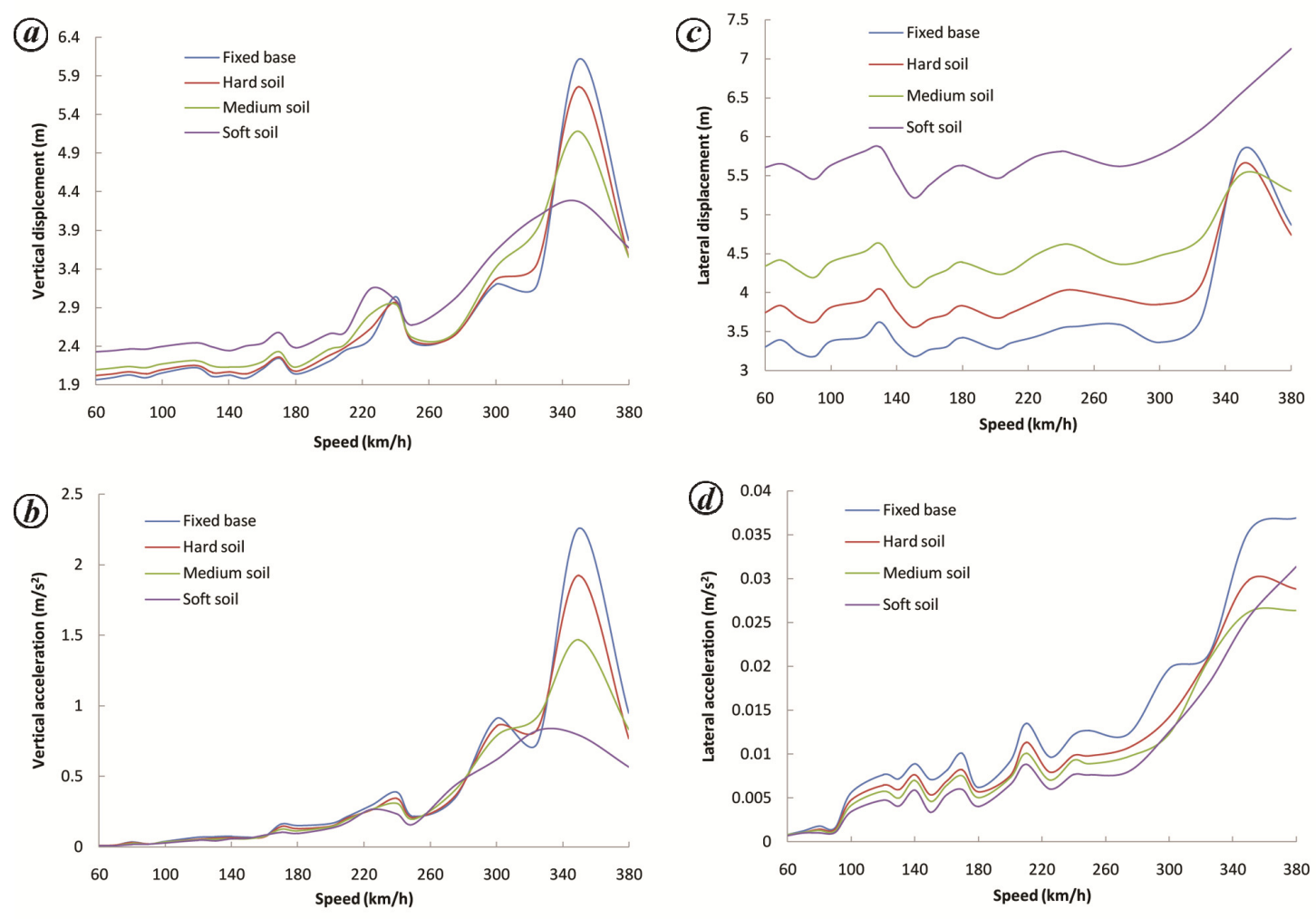

Figure 8. Mid-span maximum vertical and lateral displacement $(\boldsymbol{a}, \boldsymbol{c})$ and acceleration $(\boldsymbol{b}, \boldsymbol{d})$ response with varying train speeds of span 4 of the integral bridge. 

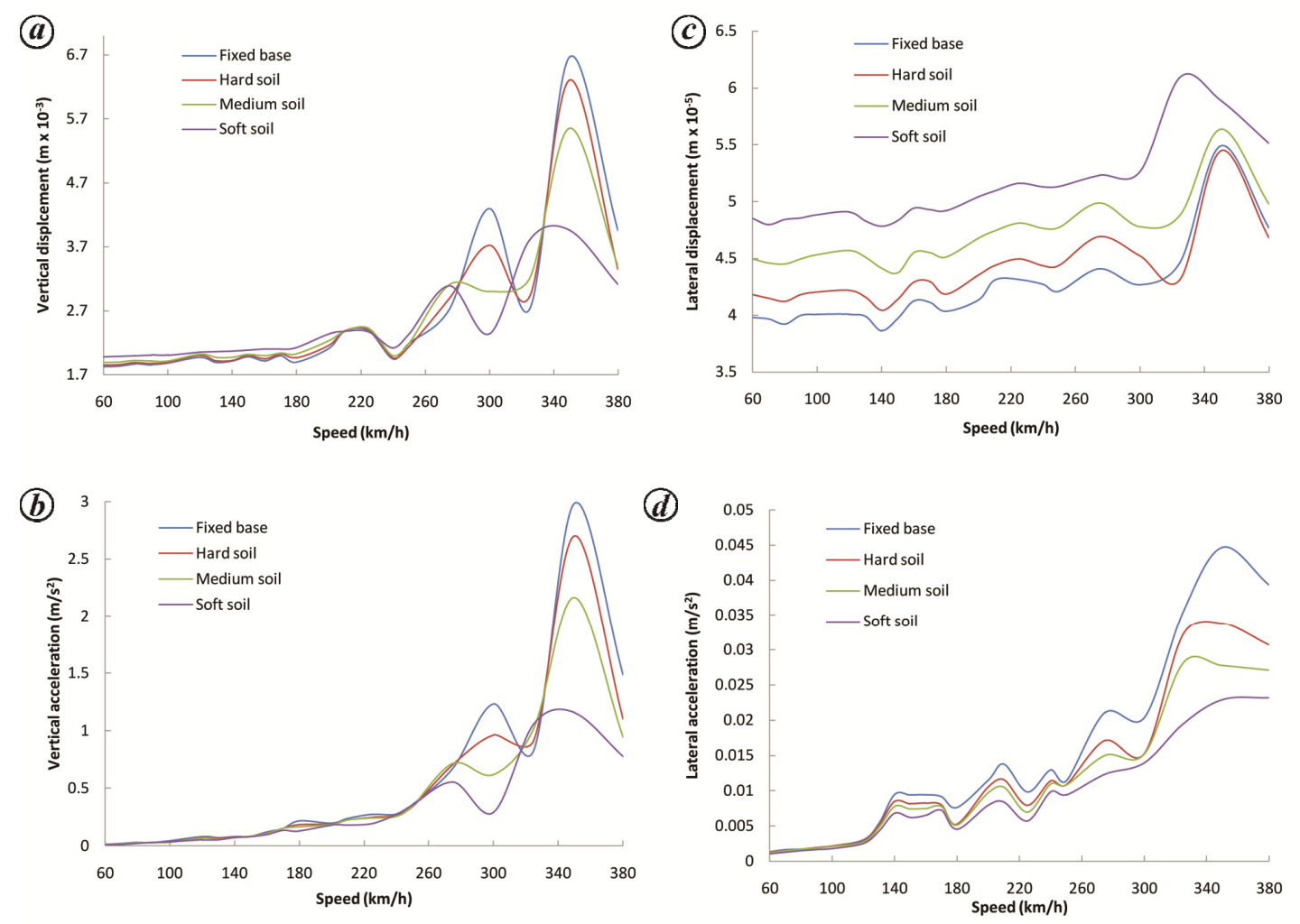

Figure 9. Mid-span maximum vertical and lateral displacement $(\boldsymbol{a}, \boldsymbol{c})$ and acceleration $(\boldsymbol{b}, \boldsymbol{d})$ response with varying train speeds of span 5 of the integral bridge.

Table 6. Mid-span resonance response of all spans of the integral bridge

\begin{tabular}{|c|c|c|c|c|c|c|c|c|c|c|}
\hline \multirow[b]{2}{*}{$\begin{array}{l}\text { Pier } \\
\text { foundation }\end{array}$} & \multicolumn{2}{|c|}{ Span 1} & \multicolumn{2}{|c|}{ Span 2} & \multicolumn{2}{|c|}{ Span 3} & \multicolumn{2}{|c|}{ Span 4} & \multicolumn{2}{|c|}{ Span 5} \\
\hline & $\begin{array}{c}\text { Resonant } \\
\text { speed } \\
(\mathrm{km} / \mathrm{h})\end{array}$ & $\begin{array}{l}\text { Corresponding } \\
\text { mode } \\
\text { number }\end{array}$ & $\begin{array}{c}\text { Resonant } \\
\text { speed } \\
(\mathrm{km} / \mathrm{h})\end{array}$ & $\begin{array}{l}\text { Corresponding } \\
\text { mode } \\
\text { number }\end{array}$ & $\begin{array}{l}\text { Resonant } \\
\text { speed } \\
(\mathrm{km} / \mathrm{h})\end{array}$ & $\begin{array}{l}\text { Corresponding } \\
\text { mode } \\
\text { number }\end{array}$ & $\begin{array}{l}\text { Resonant } \\
\text { speed } \\
(\mathrm{km} / \mathrm{h})\end{array}$ & $\begin{array}{l}\text { Corresponding } \\
\text { mode } \\
\text { number }\end{array}$ & $\begin{array}{l}\text { Resonant } \\
\text { speed } \\
(\mathrm{km} / \mathrm{h})\end{array}$ & $\begin{array}{c}\text { Corresponding } \\
\text { mode } \\
\text { number }\end{array}$ \\
\hline Fixed base & 300,350 & 4,5 & 350 & 5 & 300 & 4 & 350 & 5 & 300,350 & 4,5 \\
\hline Hard soil & 300,350 & 4,5 & 350 & 5 & 300 & 4 & 350 & 5 & 300,350 & 4,5 \\
\hline Soft soil & 325 & 5 & 325 & 5 & 288 & 4 & 325 & 5 & 328 & 5 \\
\hline
\end{tabular}

Figure $9 a$ and $d$ represents the mid-span vertical and lateral displacement, and acceleration response.

Table 6 provides the information on resonant speeds corresponding to mode numbers for all the four soil conditions. It can be observed that for the middle span 3, resonance is obtained at mode number 4. Also, the magnitude of the dynamic response for this span for each soil condition is greater compared to other spans at a speed of $300 \mathrm{~km} / \mathrm{h}$. Thus, this span is considered for further study. The lateral response of each span is similar to the vertical response. Since track irregularities and inertia effects of the vehicle are neglected, accurate lateral bridge response is difficult to justify in the absence of an experimental study. Nevertheless, owing to the 3D bridge modelling, a fair amount of dynamic response in the lateral direction may be anticipated.

\section{Analysis of continuous bridge}

Keeping all the parameters (dimensions, cross-section details of super- and sub-structure, material properties and soil type) of the aforesaid integral bridge, and the external loading condition the same, a continuous bridge was modelled by altering the support conditions of the bridge deck. Figure 10 shows details of continuous bridge considered for moving load analysis on a single track. Medium soil type below the pier foundation was considered to compare the dynamic response of integral and continuous bridges. The dynamic soil spring and damping values for medium soil type were referred from Table 4. Table 7 summarizes the essential dynamic soilbridge interaction analysis parameters for this continuous bridge.

CURRENT SCIENCE, VOL. 116, NO. 6, 25 MARCH 2019 
RESEARCH ARTICLES

Table 7. Dynamic soil-structure interaction properties required for analysis of continuous bridge

\begin{tabular}{llcl}
\hline Mode number & \multicolumn{1}{c}{ Frequency $(\mathrm{Hz})$} & Modal damping (\%) & Rayleigh damping constants \\
\hline 1 & 1.612 (lateral floating) & 1.7 & $a_{0}=0.2411 \mathrm{~s}^{-1}, a_{1}=1.007 \times 10^{-3} \mathrm{~s}$ \\
2 & 2.286 (first vertical symmetrical bending) & \\
3 & 2.739 (first vertical anti-symmetrical bending) & \\
4 & 3.297 (second vertical symmetrical bending) & \\
5 & 3.764 (second vertical anti-symmetrical bending) & \\
\hline
\end{tabular}

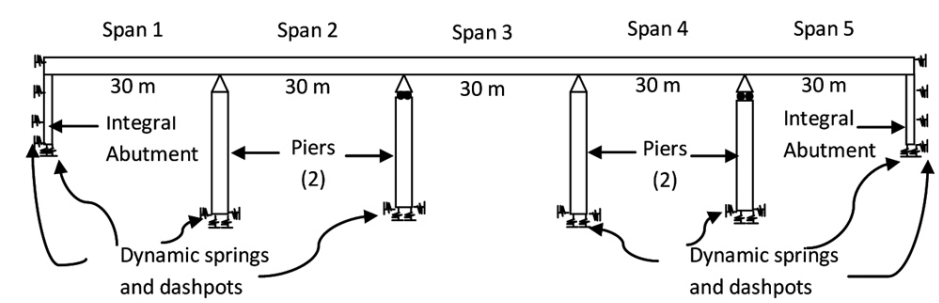

Figure 10. Continuous bridge considered for the dynamic soil-structure interaction analysis.
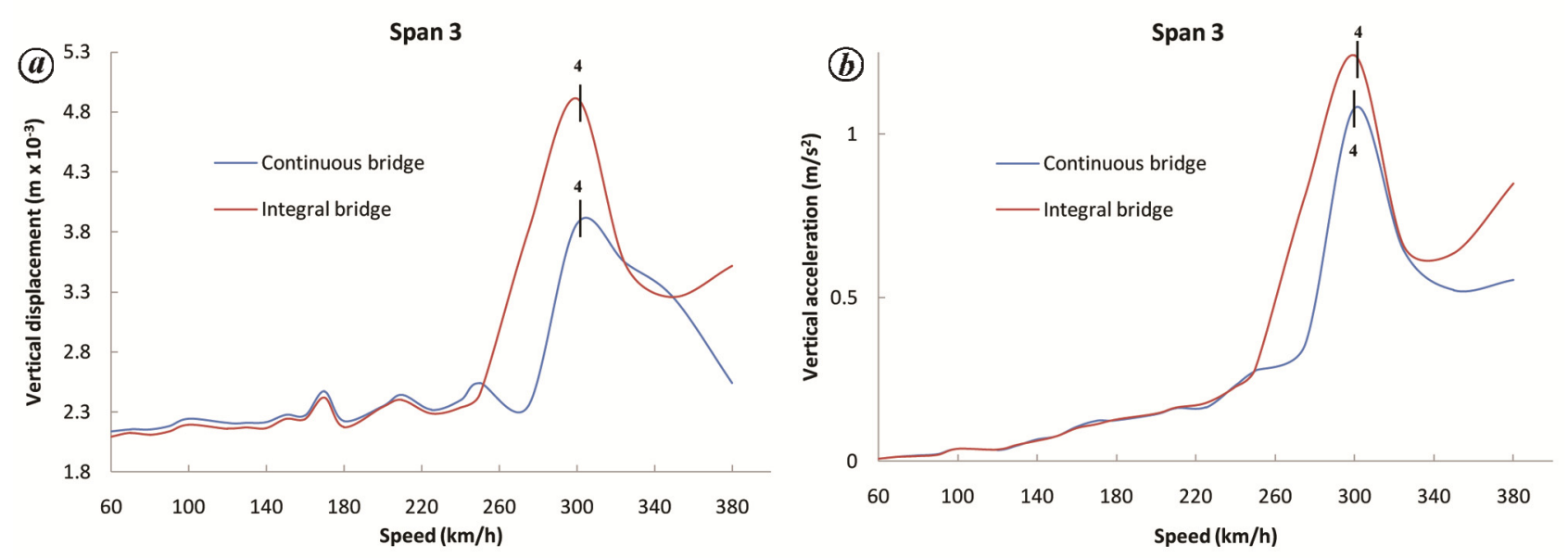

Figure 11. (a) Maximum mid-span displacement and (b) acceleration response of the continuous and integral bridge decks with varying moving load speeds. Vertical solid black lines and numerals represent the resonant mode numbers.

\section{Comparison of continuous and integral bridge response}

The dynamic response of a continuous bridge certainly shows variation compared to the integral bridge. As discussed earlier, the centre span 3 of integral bridge being a critical one, its dynamic response was compared with span 3 of the continuous bridge. Figure 11 shows a comparison between the maximum mid-span vertical displacement and acceleration response varying with increasing moving load speeds of the integral and continuous bridges. It can be noted that for both the bridges, the resonance response is obtained at mode number 4 (shown by vertical black solid lines in Figure 11) and hence, at higher speeds. Also, the dynamic responses increase with increase in train speed. Integral bridge being stiff compared to the continuous bridge, an obvious shift (more than the continuous bridge) of both the vertical displacement and acceleration response at resonance can be clearly seen. The difference in the resonant speeds is not much as the resonance frequencies of these two bridges for medium soil condition are comparable. Figures 12 and 13 show the time histories of mid-span vertical displacement and acceleration at resonance for the continuous and integral bridge respectively. It is evident from these two figures that the displacement and acceleration response of the continuous bridge is more than the integral bridge till resonance is reached. From Figures $12 a$ and $13 a$, it can be observed that the mid-span vertical displacement at resonance of integral bridge is $27 \%$ more compared to the continuous bridge. Thus, for the present study, the vertical resonant response of the integral bridge is high compared to the continuous bridge.

This article discussed the mid-region vertical and lateral responses of all the spans of a 3D full-scale integral bridge. Because moving loads/forces are considered in 

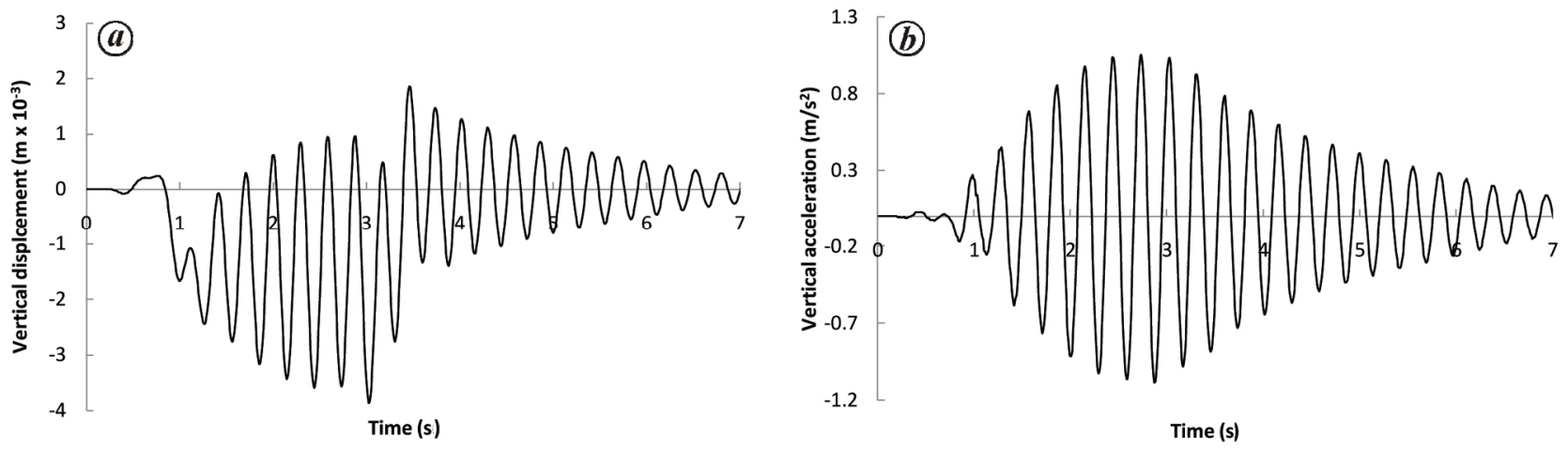

Figure 12. Time histories of (a) vertical displacement and (b) vertical acceleration of mid-span ( $\operatorname{span} 3)$ of the continuous bridge at resonance.
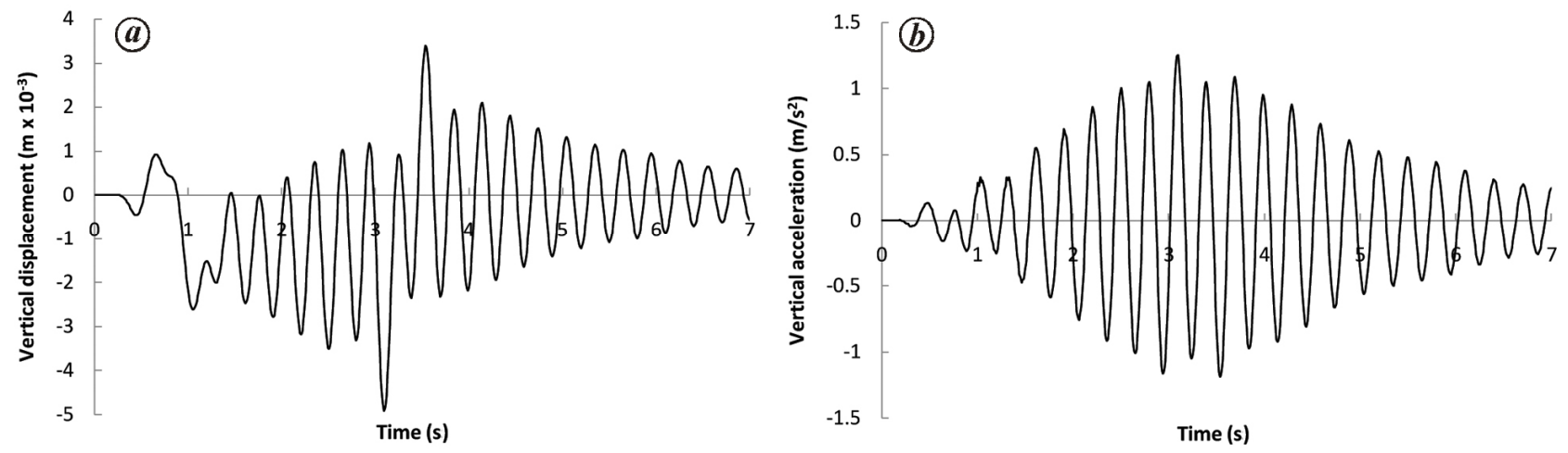

Figure 13. Time histories of $(\boldsymbol{a})$ vertical displacement and $(\boldsymbol{b})$ vertical acceleration of mid-span (span 3$)$ of the integral bridge at resonance.

the analysis, the inertial effects of this vehicle are neglected. This assumption may not provide the actual lateral dynamic response of the bridge structure. However, the vertical response is not affected much ${ }^{19}$. This study is related to the effects of SSI on resonance excitations, produced due to high-speed moving loads, of the superstructure alone. Thus, the vehicle (train) response is of less importance and hence not discussed. Nevertheless, for assessing passenger comfort, train-bridge interaction study is essential. This may form an extension of the present study. Further, analysis of a 3D full-scale doubletrack integral model, under high-speed moving trains on both the tracks crossing each other, can be carried out.

\section{Observations and discussion}

In this study two types of multi-span bridges were analysed, viz. integral and continuous. For the integral bridge, different soil conditions below the pier foundation to carry out a dynamic soil-bridge interaction analysis subjected to high-speed moving loads running on a single track were considered. The resonance response (vertical and lateral) of mid-span of each span of the bridge deck was studied. From the analyses it can be concluded that:
- For all the five spans and for all the considered soil conditions, the resonance peaks (vertical response) are obtained at speeds corresponding to higher modal frequencies (mode numbers 4 and 5).

- For the lateral response of all these spans, similar condition as discussed above is obtained. These values are too small and are presented in the study merely to show the contribution of moving loads in the lateral direction on a full-scale $3 \mathrm{D}$ bridge finite element model.

- Resonance peaks and resonant speeds for the corresponding lower modal frequencies (mode numbers 13) cannot be seen.

- Span 3 (middle span) is a critical one since, the magnitude of its resonance peak corresponding to mode number 4 is greater compared to the other spans with the same mode number. This is true for all soil types.

- Fixed base condition overestimates the dynamic response of the superstructure. The dynamic SSI analysis shows reduction of resonance amplitude, thus emphasizing its importance.

A comparative dynamic analysis of the integral and continuous bridges for medium soil condition was worked out. The middle span of both these bridges was analysed 
to observe its vertical resonance response. The following points were noted:

- For both the bridges, resonance response was obtained at the higher mode number 4.

- The magnitude of resonance response for the integral bridge was more than that of the continuous bridge.

\section{Conclusion}

Thus, from the above discussion it can be concluded that the resonance response is certainly observed for different spans of an integral bridge under high-speed moving loads on a single track. The variation of resonance peak is evident for different soil conditions and hence for different modal damping ratios. From this study, it is clear that a detailed dynamic SSI analysis under high-speed moving loads is essential to obtain the resonance response of integral bridges. A detailed study of the dynamic soilintegral bridge interaction under high-speed trains moving on both the tracks is suggested.

1. Marx, S. and Seidl, G., Integral railway bridges in Germany. Struct. Eng. Int., 2011, 3, 332-340.

2. Faraji, S., Ting, J. M., Crovo, D. S. and Helmut, E., Nonlinear analysis of integral bridges: finite-element model. J. Geotech. Geoenviron. Eng., 2001, 127, 454-461.

3. Shoukry, S. N., William, G. W. and Riad, M. Y., Response of an integral abutment bridge to temperature variations. In Proceedings of Structures Congress: Crossing Borders, ASCE, Reston, VA, 2008, pp. 1-10.

4. Javier, R., Francisco, M. and Joaquin, M., Integral bridge for highspeed railway. Struct. Eng. Int., 2011, 3, 297-303.

5. Shamsabadi, A. and Kapuskar, M., Nonlinear soil-abutmentfoundation-structure interaction analysis of skewed bridges subjected to near-field ground motions. Transp. Res. Rec.: J. Transp. Res. Board, 2010, 2202, 192-205.

6. Fry'ba, L., A rough assessment of railway bridges for high-speed trains. Eng. Struct., 2001, 23(5), 548-556.

7. Kwark, J. W., Choi, E. S., Kim, Y. J., Kim, B. S. and Kim, S. I., Dynamic behavior of two-span continuous concrete bridges under moving high-speed train. Comput. Struct., 2004, 82(4-5), 463474.

8. Wang, Y., Wei, Q. C., Shi, J. and Long, X., Resonance characteristics of two-span continuous beam under moving high speed trains. Latin Am. J. Solids Struct., 2010, 7, 185-199.
9. Yau, J. D., Resonance of continuous bridges due to high speed trains. J. Mar. Sci. Technol., 2001, 9(1), 14-20.

10. Li, X. Z., Liu, X. H., Liu, D. J. and Zhang, X., Influences of soilstructure interaction on coupled vibration of train-bridge system: theoretical and experimental study. Adv. Struct. Eng., 2013, 16(8), 1355-1364.

11. Wu, Y. S., Yang, Y. B. and Yau, J. D., Three-dimensional analysis of train-rail-bridge interaction problems. Veh. Syst. Dyn., 2001, 36 (1), pp. 1-35.

12. Ülker-Kaustell, M., Karoumi, R. and Pacoste, C., Simplified analysis of the dynamic soil-structure interaction of a portal frame railway bridge. Eng. Struct., 2010, 32, 3692-3698.

13. Yang, Y. B., Yau, J. D. and Wu, Y. S., Vehicle-Bridge Interaction Dynamics with Applications to High-Speed Railways, World Scientific, USA, 2004.

14. SAP2000, Integrated structural analysis and design software Computers and Structures Inc., Berkeley, California, USA, 2005.

15. Gazetas, G., Formulas and charts for impedances of surface and embedded foundations. J. Geotech. Eng., 1991, 117(9), 13631381.

16. Chopra, A. K., Dynamics of Structures: Theory and Applications to Earthquake Engineering, Prentice-Hall of India, New Delhi, 2008, 3rd edn.

17. European Committee for Standardisation (CEN). Eurocode1: actions on structures - part 2: traffic loads on bridges, 2003.

18. Fry'ba, L., Vibration of solids and structures under moving loads. Thomas Telford, 1999.

19. Liu, K., Reynders, E., DeRoeck, G. and Lombaert, G., Experimental and numerical analysis of a composite bridge for high-speed trains. J. Sound Vibr., 2009, 320, 201-220.

20. Zeng, Z., Zhu, K., He, X., Xu, W., Chen, L. and Lou, P., Random vibration analysis of train moving over slab track on bridge under track irregularities and earthquakes by pseudo excitation method. Discrete Dyn. Nat. Soc., 2015, 2015, 1-22.

21. Wang, S. J., Xu, Z. D., Li, S. and Dyke, S. J., Safety and stability of light-rail train running on multispan bridges with deformation. J. Bridge Eng., 2016, 21(9), 1-7.

22. Lei, X., Wu, S. and Zhang, B., Dynamic analysis of the high speed train and slab track nonlinear coupling system with the cross iteration algorithm. J. Nonlinear Dyn., 2016, 2016, 1-17.

ACKNOWLEDGEMENT. We thank the anonymous reviewers for their valuable comments and suggestions that helped improve the manuscript.

Received 2 February 2018; revised accepted 26 December 2018

doi: $10.18520 / \mathrm{cs} / \mathrm{v} 116 / \mathrm{i} 6 / 972-981$ 